\title{
O CARACAZO NA VENEZUELA (1989): DA CRÍTICA AO PRESENTISMO A UMA PERSPECTIVA ACONTECIMENTAL DA HISTÓRIA
}

\author{
THE CARACAZO IN VENEZUELA (1989): FROM THE PRESENTISM'S \\ CRITICISM TO AN EVENTUAL PERSPECTIVE FOR HISTORY
}

\begin{abstract}
Livia Vargas-González ${ }^{1}$
RESUMO: No presente artigo proponho-me a descrever a irrupção popular do Caracazo, acontecida na Venezuela em 27 e 28 de fevereiro do ano 1989, à luz da ruptura que ele gerou no regime democrático representativo venezuelano, bem como a reviravolta que significou diante da expansão do neoliberalismo no mundo após a queda do bloco soviético. A minha hipótese, a qual assume o Caracazo como acontecimento, toma como base o debate sobre a potencialidade das apostas emancipatórias hoje, tendo como premissa a ideia segundo a qual a história continua aberta às emergências acontecimentais, entendidas como chance messiânica. A descrição do Caracazo oferece outra referência da história efetiva que se constitui em chave para pensarmos uma concepção aberta da história na qual a questão da conjuntura e da estratégia ocupam um lugar relevante.
\end{abstract}

PALAVRAS-CHAVE: acontecimento, Caracazo, história aberta, "algarabía" messiânica, tragédia traumática.

ABSTRACT: In the present essay, I intend to describe the popular irruption of "Caracazo", which took place in Venezuela on February 27 and 28, 1989, taking into consideration the rupture that it generated in the representative democratic regime in Venezuela, as well the reversal that it meant for the expansion of neoliberalism in the world after the fall of the Soviet bloc. My

* O presente artigo se desprende das discussões e reflexões geradas com os meus companheiros André Luan, Larissa de Assis e Ana Malaco, no marco da disciplina Teorias Contemporâneas do Tempo Histórico, ministrada pelo Prof. Dr. Valdei Araujo, no Programa de Pós-Graduação em História da Universidade Federal de Ouro Preto (UFOP). Aliás, ele faz parte das notas e reflexões da minha pesquisa doutoral, intitulada "Potências e im-potências do Sacudón", orientada pelo professor Dr. Marcelo de Mello Rangel, no mesmo programa de pós-graduação e sob financiamento da Coordenação de Aperfeiçoamento de Pessoal de Nível Superior (CAPES).

${ }^{1}$ Formada em Filosofia, com mestrado em Filosofia e Ciências Humanas pela Universidade Central da Venezuela (UCV). Professora de Teoria Social na Escola de Sociologia da Universidade Central da Venezuela (UCV) e Doutoranda no Programa de Pós-Graduação em História da Universidade Federal de Ouro Preto (UFOP) 
hypothesis, which describes the "Caracazo" as an event, takes as its starting point the debate about the potential of emancipatory bets today, based on the idea that history continues to be open to the unexpected emergency of event, understanding it as chance messianic. The description of the "Caracazo" offers another example of effective history that it is a key for us think about an open conception of history in which conjuncture and strategy are very significant.

KEYWORDS: event, Caracazo, open history, messianic gibberish, traumatic tragedy.

"El tiempo se bifurca perfectamente hacia innumerables futuros". Jorge Luis Borges, "El jardín de los senderos que se bifurcan" (1984: p. 379).

"No estoy arrepentida. Fue un saqueo honrado. En mi casa hay comida y cuatro bermudas, una franela, un par de zapatos y una correa para mí. ¿Lo volvería a hacer? No sé”.

Testemunho de uma senhora, Diario de Caracas, 07/03/1989 (apud COLMENAREZ, 1989).

O contexto de nosso debate: irrupções em tempos de presentismo?

No ano 2017, a cidade de Charlottesville, nos Estados Unidos, foi declarada em estado de emergência depois que defensores da supremacia branca, grupos neonazistas e figuras representativas do $\mathrm{Ku}$ Klux Klan convocaram um protesto pela "Unidade da direita" em repúdio à demolição da estátua de Robert Lee, um general confederado na Guerra Civil dos Estados Unidos e oponente fervoroso à abolição da escravidão. A manifestação, confrontada por jovens, estudantes negros e militantes de agrupações antirracistas, desdobrou-se numa situação de violência que deixou um importante saldo de mortos, feridos e detidos.

$\mathrm{Na}$ véspera do protesto, os supremacistas brancos saíram com suas tochas no punho até a Universidade de Virgínia com o intuito de "preparar" e "esquentar" a convocatória do dia seguinte. Suas consignas, acompanhadas de manifestações explícitas de violência, estiveram dirigidas contra os negros, os gays, os judeus e os imigrantes. Entretanto, jovens antifascistas e estudantes 
negros da universidade tentaram opor-se ao protesto, mas foram cercados e ameaçados pelos supremacistas.

Eu destaco a singularidade deste episódio - que não fica muito distante do cenário social e cultural no Brasil hoje - não apenas pela manifestação aberta de ações políticas antidemocráticas, racistas e discriminatórias, que parecem pôr em risco a solidez da institucionalidade democrática moderna, mas sobretudo pelos chamados e pelas ações de auto-organização geradas posteriormente por parte dos grupos antifascistas com a população discriminada da Virgínia - negros, gays, mulheres e imigrantes - (GUERRILLA COMUNICACIONAL MÉXICO, 2017), dos quais destaca-se a emergência de forças de resistência que confrontam tais ações de poder opressivas e antidemocráticas. Mais do que intimidação e paralisia, as afrontas dos supremacistas brancos geraram uma reação de desafio e de coragem na comunidade discriminada.

Diante da cumplicidade do Estado para não conter o avanço racista nos Estados Unidos, esses movimentos e organizações antirracistas e antifascistas optaram pela autodefesa, portando armas de fogo e se organizando com a comunidade. Tratou-se de mecanismos de organização e de ação política que retornaram depois de terem perdido legitimidade como opções de luta e de resistência.

Esta vontade auto-organizativa por parte dos setores afastados e discriminados da população, manifesta-se em outros pontos do orbe e do tempo atual. Mais recentemente, e em resposta à tentativa de imposição do pacote de medidas econômicas acordado entre o governo Lenin Moreno e o Fundo Monetário Internacional (FMI), os indígenas no Equador conseguiram, com seus arcos, flechas e vontade, pôr em xeque o governo, o qual acabou mudando a sede de Quito para Guayaquil. Na França, os operários não só paralisaram o serviço de transporte e as máquinas nas fábricas, mas definiram e levaram para frente políticas e estratégias de distribuição de bens e serviços para os setores desfavorecidos no país.

Hong Kong, Haiti, Chile, são outros exemplos de situações nas quais virara 
a correlação de forças entre a ordem estabelecida e a população discriminada e oprimida, abrindo novas possibilidades para a reconfiguração do futuro e das relações sociais, e em um contexto que, após as derrotas das apostas revolucionárias do século $\mathrm{XX}$, leva o peso do espírito das resignações diante da ordem do capital.

Do passado século $\mathrm{XX}$, nós recebemos como herança uma crise na representação da história enquanto linearidade e progresso, bem como das grandes ideias-força com as quais a modernidade hegemônica ${ }^{2}$ se sustentara. Diante do colapso do bloco soviético, da expansão neoliberal e das ameaças cada vez mais próximas da finitude da vida no planeta, o fim das utopias, o fim da história, o fechamento do futuro e a ideia de um presente expandido sustentadas nas hipóteses do "presentismo" e do no future -, conseguiram se constituir nas fórmulas explicativas do nosso tempo e das suas possibilidades.

Desta forma, o decreto de morte da história que fizera Francis Fukuyama na revista The National Interest (1988), converteu-se em tese definitiva para boa parte da literatura teórica nas humanidades e nas ciências sociais.

Naquele artigo, Fukuyama afirma

lo que podríamos estar presenciando no sólo es el fin de la guerra fría, o la culminación de un período específico de la historia de la posguerra, sino el fin de la historia como tal: esto es, el punto final de la evolución ideológica de la humanidad y la universalización de la democracia liberal occidental como la forma final de gobierno humano (FUKUYAMA, 1990: 6 e seq.).

Esta era pós-histórica de futuros fechados terá os mesmos traços do mundo desencantado de Weber: um mundo triste, sem arte, sem filosofia, submetido à fria aridez da técnica e sem quaisquer manifestações coletivas de vontade, coragem, nem imaginação para pensar e lutar por sonhos e projetos de transformação social (FUKUYAMA, 1990: 31). Trata-se de um mundo “zumbi”, marcado pelo clima das resignações.

\footnotetext{
${ }^{2}$ Falo de "modernidade hegemônica" e não apenas de "modernidade", tentando dar conta do caráter heterogêneo dos processos históricos e das narrativas que se impõem nessa tensão. Nesse sentido, apoio-me na hipótese de Bolívar Echeverría, segundo a qual na modernidade concorrem projetos de futuro em disputa. Ver (ECHEVERRÍA, 2011).
} 
Por sua vez, a hipótese presentista, formulada por François Hartog (2007), propõe que nosso presente se desenvolve num tempo cujas dimensões temporais - passado, presente e futuro - perderam suas fronteiras e/ou suas linhas de continuidade, estabelecendo o "presentismo" como "la experiencia contemporánea del tiempo" (HARTOG, 2007: 15). Nosso presente, animado pelo imediato dos mercados, pela globalização e pelas comunicações em tempo real, inscreve-se numa experiência do tempo marcada por uma crise do futuro, ou seja, por uma ruptura da continuidade histórica que, ao fraturar a relação entre passado, presente e futuro e diluir as expetativas diante do porvir, instaura um espírito de paralisia "poiética" perante a incerteza.

$\mathrm{Na}$ tentativa de compreender a experiência contemporânea do tempo, Hans Ulrich Gumbrecht concebe a ideia de um presente expandido e inundado pelo passado, no qual o futuro não é mais um horizonte aberto de possibilidades. "Entre os passados que nos engolem e o futuro ameaçador, o presente transformou-se em uma dimensão de simultaneidades que se expandem" (GUMBRECHT, 2015: 16). Com um futuro fechado que impede qualquer projeção, a ação fica impotente de se realizar.

A partir do que estas perspectivas sobre a experiência contemporânea do tempo diagnosticam, o horizonte emancipatório e transformador, muito presente nas narrativas modernas da história, dilui-se e se apaga. No entanto, episódios disruptivos como os de Charlottesville, Chile, Equador, Hong Kong, Haiti, dentre outros, manifestam pulsões que se contrapõem ao sentimento de desesperança e de resignações que acompanha a narrativa presentista do nosso tempo.

Todavia, como refletir sobre os processos sociais e históricos que, em nosso presente, tentam ultrapassar os limites do capital, à luz das derrotas estratégicas do passado século XX?

Outras tradições do pensamento contemporâneo tentam refletir sobre a crise do futuro, sem abandonar as possibilidades emancipatórias e reconhecendo as dificuldades que derivam da restituição de uma temporalidade histórica que transpõe tanto as narrativas do progresso histórico quanto as que 
fecham a temporalidade no imediato.

Bebendo das fontes de Martin Heidegger, Mateus Pereira e Valdei Araujo (PEREIRA e ARAUJO, 2016) propõem a hipótese do "atualismo" para dar conta das formas nas quais se produz a experiência contemporânea do tempo. Segundo eles,

nosso presente não precisa ser pensado apenas como presente alargado, ou como um presente sem futuro, mas como uma forma de temporalização que assentada em um modo específico do presente articula futuro e passado. Chamamos esse modo ou condição extrema de atualismo (PEREIRA e ARAUJO, 2016: 294).

Segundo a hipótese atualista, a experiência contemporânea do tempo se produz de forma autêntica ou inautêntica. No primeiro caso, o tempo é experimentado pela presença enquanto antecipação, projetando-se para o que poderia ser. No segundo caso, o tempo é experimentado pela presença enquanto espera, assumindo uma disposição passiva, carregada de angústia. Desta forma, nosso presente se movimenta num paradoxo que, sem desconhecer suas formas inautênticas, mostra uma dimensão autêntica que estabelece uma relação não fechada nem passiva com o futuro.

Perspectivas acontecimentais da história: a aposta pela abertura disruptiva

Além das perspectivas anteriores, as quais enfatizam a centralidade do presente na experiência contemporânea do tempo histórico, há, aliás, outras referências teóricas que rebatem a hipótese presentista. Refiro-me particularmente às perspectivas propostas por Slavoj Zizek, Daniel Bensaïd e Alain Badiou, as quais, para além das suas particularidades e diferenças, compartilham uma concepção aberta da história que coloca a ênfase na ideia de "singularidade", "descontinuidade" e "ruptura". Essas perspectivas restituem o debate sobre as possibilidades emancipatórias após o colapso do bloco soviético e propõem um olhar político-estratégico da história no qual o "acontecimento" constitui-se na chave compreensiva dos processos que irrompem a estabilidade e a continuidade histórica, visando à sua potencialidade "práxico"-concreta. É 
na inscrição do "impossível" no plexo de relações, dinâmicas e forças que perambulam no âmbito do estabelecido onde reside a potencialidade "práxica" do "acontecimento".

Segundo Alain Badiou, a fertilidade emancipatória do "acontecimento" encontra-se na sua diferenciação a respeito da situação na qual ele emerge. Trata-se de uma emergência cujas razões excedem o estado de coisas. Desta forma, o "acontecimento" não é

a realização de uma possibilidade interna à situação ou dependente das leis transcendentais de um mundo. Um acontecimento é a criação de novas possibilidades. Ele se situa, não simplesmente ao nível dos possíveis objetivos, senão da possibilidade dos possíveis.

Isto pode se dizer também assim: em relação com a situação ou o mundo, um acontecimento abre à possibilidade do que, do estrito ponto de vista da composição desta situação ou da legalidade de este mundo, é propriamente impossível. ${ }^{3}$

O "acontecimento" é, nesta perspectiva, a inauguração de um processo de verdade $^{4}$ a partir do qual o sujeito realiza e torna efetiva a transformação da situação; um processo de verdade que coloca o centro da sua realização em um imperativo, isto é, na exigência de um ato de fidelidade ao "acontecimento" que torna possível sua subsistência no marco de tensões com a estrutura e com o mundo.

No entanto, o "acontecimento" pressupõe a quebra não só do próprio real, mas do plexo de sentidos e representações. Trata-se, segundo Slavoj Zizek (ZIZEK, 2014), de um conceito "polissêmico" que se mobiliza na oscilação entre uma dimensão transcendental - a qual atinge a forma em que se nos apresenta a realidade - e uma dimensão ôntica - o momento da emergência e expansão do próprio real -, e cuja descrição filosófica deve ter como ponto de partida o reconhecimento de sua natureza anfíbia.

\footnotetext{
3 "la réalisation d'une possibilité interne à la situation, ou dépendante des lois transcendentales d'un monde. Un événement est la création de nouvelles possibilités. Il se situe, non pas simplement au niveau des possibles objectifs, mais à celui de la possibilité des possibles.

Ce qui peut aussi se dire: au regard de la situation ou du monde, un événement ouvre à la possibilité de ce qui, du strict point de vue de la composition de cette situation ou de la légalité de ce monde, est proprement imposible" (BADIOU, 2009: 191, tradução minha).

${ }^{4}$ Badiou introduz a dimensão ética e política ao definir a fidelidade ao acontecimento como aquilo que sustenta o processo de produção de verdade. (BADIOU, 2010; BADIOU, 2003).
} 
Desta descrição ressalto, pelo menos, quatro acepções da ideia de "acontecimento". 1) Enquanto trauma, trata-se de algo "perturbador, que parece suceder de repente y que interrumpe el curso normal de las cosas; algo que surge aparentemente de la nada, sin causas discernibles, una apariencia que no tiene como base nada sólido" (ZIZEK, 2014: 16) e que, ao ser monstruosa, revela o real, derruba as representações que configuram a realidade e quebra os mitos com os quais ela se constitui. 2) Enquanto milagre, o "acontecimento" é extraordinário, messiânico e redentor, na medida em que inaugura, depois da catástrofe, uma nova situação, reparadora e emancipatória. 3) Enquanto causa sui, trata-se da "aparición inesperada de algo nuevo que debilita cualquier diseño estable" (ZIZEK, 2014: 17), que escapa à ordem do tempo e das coisas e obedece às suas próprias determinações. 4) Enquanto excesso, o "acontecimento" excede as suas próprias causas, tendo como seu lugar o espaço "que se abre por el hueco que separa un efecto de sus causas" (ZIZEK, 2014: 17), isto é, a ruptura que torna possível a emergência da impossibilidade do vazio na completude do estado de coisas existente.

Entendo a ruptura como o contexto crítico do estado de coisas em que o "acontecimento" emerge (BENSAÏD, 2006), bem como a zona fronteiriça da ordem social capitalista atual (BADIOU, 2003; ECHEVERRÍA, 2011), na qual habitam os elementos marginalizados ou não reconhecidos com os quais esta ordem se confronta. Embora o "acontecimento" não esteja inscrito nas esferas da realidade efetiva, ele não fica nas margens dela. Muito pelo contrário, ele irrompe nas suas "falhas", alterando-as.

Neste ponto crítico da situação e da ordem (BADIOU, 2003: 199), no qual explode o "acontecimento", é onde circulam os elementos excluídos, ocultos e discriminados por elas que, ao irromperem de forma imprevista, criam novas possibilidades materiais, simbólicas e relacionais, fundamentando-se a si mesmos.

Daniel Bensaïd concebe a crise do tempo histórico como o sintoma do nosso tempo (BENSAÏD, 2013), o qual resulta, entre outras coisas, da crise conceitual do historicismo e se manifesta num obscurecimento dos "horizontes 
de expectativa" (KOSELLECK: 1993) e em um retraimento da temporalidade política. Sua proposta, que é tanto teórica quanto política, procura restituir a ligação entre passado, presente e futuro na temporalidade histórica, a partir da inscrição da dimensão estratégica. Trata-se de uma concepção política da história na qual o presente se constitui no cenário das oportunidades estratégicas e da disputa dos possíveis por sua realização efetiva, e no qual "se juegan y vuelven a jugar en permanencia los sentidos del pasado y del futuro. Es el tiempo del desenlace entre una pluralidad de posibilidades" (BENSAÏD, 2013: 109).

Nesta concepção da história, a temporalidade de Kronos é deslocada pela temporalidade de Kairós, destacando a multiplicidade de futuros possíveis e incertos que habitam potencialmente em cada presente e cuja objetivação responde a forças, tensões, conjunturas e estratégias. Trata-se, aliás, de uma concepção que restitui, da mesma forma que o faz Michael Lowy, o caráter aberto da história.

la historia abierta significa, por lo tanto, la consideración de la posibilidad -no la inevitabilidad- de las catástrofes, por un lado, y de grandes movimientos emancipatorios, por otro. Esto dista de ser evidente: ¿no vivimos en una época pacificada, a mil leguas de distancia de los años de guerra y revolución de la primera mitad del siglo pasado? (LÖWY, 2012: 175).

Uma perspectiva aberta da história permitir-nos-á incorporar a potencialidade disruptiva do "acontecimento", bem como os seus limites e alcances na aposta teórica e política pela transformação da ordem do mundo em que nós vivemos hoje. Concebido como "chance messiânica", e não apenas como emergência "in-causada", "in-condicionada" e "imprevisível", a ideia de "acontecimento" permitir-nos-á incorporar a dimensão "práxica" e da "agência" na nossa abordagem descritiva da rebelião do Caracazo, a qual assume-o como ruptura da linearidade histórica venezuelana.

O Caracazo: do milagre à tragédia. Narração de uma emergência acontecimental 
Em 4 de junho de 1989, a Praça Tiananmen foi o cenário de uma das fotografias mais famosas de finais do século XX. Trata-se da imagem de um jovem que, em atitude de desafio, se jogou na frente dos tanques de guerra levados pelo governo chinês para reprimir o último protesto da rebelião popular e estudantil que emergira na cidade de Beijing em oposição às reformas econômicas impostas pelo governo, as quais ameaçavam a subsistência da população. A repressão gerou um saldo de 400 a 800 assassinatos, 7000 a 10.000 feridos e uma quantidade importante de detidos.

Em 30 de julho desse mesmo ano, quase dois meses depois, no Chile, centenas de milhares de pessoas manifestaram a sua vontade nas urnas eleitorais em um plebiscito para dizer NO ao regime "pinochetista", derrubando os muros da ditadura e inaugurando, pelo menos institucional e formalmente, o processo democrático nesse país.

Outubro na Hungria, novembro na Checoslováquia, novembro em Berlim, dezembro no Panamá... 1989 representa o ano das quedas, das rupturas e dos fechamentos. Enfim, o anúncio antecipado do final de século XX.

De todas estas quedas, as mais referidas são aquelas que têm dado conta do fracasso das apostas revolucionárias e que reforçam e alentam as resignações frente à ordem existente. No entanto, outras quedas, acontecidas no mesmo ano, expressam o espírito de desafio e de resistência à expansão neoliberal no mundo.

Nos dias 27 e 28 de fevereiro, começando o ano 1989, ao norte do Sul da América, uma rebelião contra o avanço neoliberal - impulsionado fundamentalmente pelo Fundo Monetário Internacional - removia os alicerces do chão. Na manhã do dia 27 de fevereiro, em Guarenas, uma cidade periférica de Caracas, a população reagiu contra o aumento dos preços das passagens. Embora o governo anunciara um aumento de $30 \%$ nos preços das passagens, os donos dos meios de transporte decidiram impor sua própria tarifa. No entanto, a arrogância destes ficou ultrapassada pela irreverência das pessoas que decidiram não aceitar o aumento e impediram a saída dos ônibus do terminal. 
Desta forma começaram as jornadas do Caracazo, uma rebelião popular que, sem previsão nenhuma, desafiou a expansão neoliberal no mundo e derrubou o mito da democracia "puntofijista", considerada uma das "mais robustas" da América Latina.

$\mathrm{Na}$ literatura historiográfica, política e sociológica existente sobre o Caracazo, uma das mais difundidas - especialmente pela narrativa oficial do governo venezuelano - é a que o concebe como o ponto de quebra do regime representativo venezuelano, bem como uma reviravolta diante da expansão neoliberal no mundo após a queda do bloco soviético ${ }^{6}$.

Segundo o extinto Partido Socialista de los Trabajadores (PST), em sua Conferência Nacional Extraordinária, realizada em junho de 1989, o Caracazo foi

una insurrección popular (...) generalizada y espontánea (...) sin dirección ni organización (...) contra el paquete económico impuesto por el gobierno (...), directamente anticapitalista, que se levanta contra la política de un gobierno 'democrático'. (...) Él abrió un hecho inédito (...): dio inicio a la crisis del aparato represivo del Estado burgués, manifiesto en la negativa de muchos soldados a disparar o ir a los barrios ${ }^{7}$ más aguerridos. (PARTIDO SOCIALISTA DE LOS TRABAJADORES, 1989: s.p.).

\footnotetext{
5 Democracia "puntofijista" é o nome com o qual se conhece o regime democrático representativo na Venezuela depois da queda da ditadura de Marcos Pérez Jiménez, em 23 de Janeiro de 1958, e cuja estrutura econômica se centra fundamentalmente na renda petroleira. O termo "puntofijista" provém do "Pacto de Punto Fijo", um acordo assinado por dirigentes do partido socialdemocrata Acción Democrática $(\mathrm{AD})$, do partido social-cristão Comité de Organización Política Electoral Independiente (Copei), e do partido socialdemocrata Unión Republicana Democrática (URD), em uma reunião realizada na fazenda Punto Fijo, em 31 de outubro de 1958. O acordo exclui o Partido Comunista de Venezuela (PCV), uma das forças políticas mais importantes na Venezuela no período da ditadura, e terá, entre seus convênios, o estabelecimento de uma aliança geoeconômica e geoestratégica com os Estados Unidos no controle dos mercados e das commodities no país, a defesa da Constituição gerada no Estado democrático, o respeito aos resultados eleitorais, a conformação de um sistema de distribuição equitativa dos cargos no Poder Executivo entre os partidos assinantes, e um programa de governo mínimo comum, que será o programa que definirá o sistema democrático representativo venezuelano nos próximos quarenta anos.

${ }^{6}$ Sobre esta perspectiva, ver Los fabricantes de la rebelión (DENIS, 2001), "Testimonios" (DENIS, GÓMEZ, \& MENDOZA, 2009) e 27 de Febrero de 1989: interpretaciones y estrategias (ITURRIZA LÓPEZ, 2006). Ver, aliás, as declarações do ex-presidente da Venezuela, Hugo Chávez Frías, ao se comemorarem 21 anos do Caracazo (CHÁVEZ FRÍAS, 2010).

${ }^{7} \mathrm{Na}$ Venezuela chama-se barrios apenas as favelas.
} 
Autores como Roland Denis concebem o Caracazo como "un movimiento de ruptura inaugural de la historia y de allí su carácter profundamente revolucionario" (DENIS, GÓMEZ, MENDOZA, s.f.: p. 45). Há, todavia, aqueles que pensam que o Caracazo, embora fosse um episódio traumático, não conseguiu quebrar a continuidade histórica do regime capitalista em nosso país:

El 27 de Febrero fue un drama, un episodio de arrojo popular que terminó en tragedia (...). El $27 \mathrm{~F}$ condujo a un reflujo conservador en la lucha de clases. A pesar de haber sido una chispa de ilusión revolucionaria, la inexistencia de dirección organizada muestra que el arte de la insurrección (...) es todavía la única estrategia (...) de transformación política profunda que puede llevar a los oprimidos a la victoria definitiva sobre el capital. (SUTHERLAND, 2009: 43).

Para além destas apreciações, o que pode nos mostrar uma aproximação descritiva do Caracazo à luz dos seus alcances, limites e potencialidades, tendo em vista a preocupação teórica pela história do nosso tempo presente e, em particular, pelas possibilidades emancipatórias que podem se desprender dela? A minha hipótese, a qual assume o Caracazo como "acontecimento", toma como base o debate sobre a potencialidade das apostas emancipatórias hoje, tendo como premissa a ideia segundo a qual a história está aberta às "emergências acontecimentais".

\section{Os movimentos do Caracazo: da algarabía $^{8}$ messiânica à tragédia traumática}

Eu concebo o Caracazo como uma referência chave da história efetiva para pensar uma experiência histórica que se confronta com o espírito de resignação pós-soviético. Fazendo ênfase nas forças, sujeitos e tensões que o produziram, pretendo tramar sua abordagem descritiva a partir da narração do episódio em dois momentos: o primeiro, ao que eu chamo de "algarabía messiânica", tratase do momento da irrupção popular contra as medidas neoliberais acordadas entre o governo de Carlos Andrés Pérez (CAP) e o Fundo Monetário

\footnotetext{
${ }^{8}$ Adotando a acepção coloquial venezuelana do termo, chamo de algarabía aquele barulho e ambiente festivo, coletivo e desorganizado que é produto de uma felicidade extrema. Eu preferi manter o termo na língua hispana para não transgredir sua carga semântica.
} 
Internacional (FMI); o segundo, ao qual eu chamo de "tragédia traumática", é o da restituição da ordem institucional através de uma repressão massiva, sem precedentes na história do regime democrático "puntofijista" na Venezuela. Para isso, apoio-me em testemunhos, reflexões e dados tomados de documentários, relatórios, artigos e ensaios que refletem sobre o Caracazo, bem como em notícias de alguns jornais nacionais no período entre fevereiro e março de 1989.

\section{Primeiro movimento: a algarabía messiânica}

Em dois de fevereiro de 1989, Carlos Andrés Pérez (CAP) ${ }^{9}$ toma posse do seu cargo como Presidente da República da Venezuela, num faustoso evento que ficará resenhado pelos jornais nacionais como "A coroação". Nesse dia, convidados especiais, entre os quais destacam Daniel Ortega, Jimmie Carter e Fidel Castro, serão testemunhas da interpretação, pela segunda vez na Venezuela e na América, da Oitava Sinfonia de Gustav Mahler, a qual foi executada por mais de 1.500 músicos, entre coristas e instrumentistas.

A extravagância daquele evento contrastara com as medidas de austeridade que CAP aplicara em seu programa de governo e das quais já dera algumas pistas no seu discurso de posse: sob o seu mandato acabara a ideia do "Estado intervencionista e benfeitor" (EL MUNDO, 1989: p. 1) e se iniciara um processo de liberalização da economia, prometendo anunciar as medidas nos trinta dias seguintes.

Em 16 de fevereiro, CAP anuncia em rede nacional o pacote de medidas econômicas que seriam executadas como parte dos acordos previstos com o Fundo Monetário Internacional (FMI): incremento das tarifas dos serviços de transporte público, água, luz, telefone e gás doméstico; aumento dos preços da gasolina; liberalização dos preços de bens e produtos da cesta básica; liberalização das taxas de juro; liberalização dos preços do dólar; privatização da Educação Superior e das empresas do Estado; eliminação das taxas de

\footnotetext{
${ }^{9}$ Carlos Andrés Pérez será chamado CAP no jargão popular venezuelano. Eu manterei esta forma popular de nomeá-lo, ao longo da narrativa.
} 
importação. As medidas abririam as portas da Venezuela para a economia neoliberal e gerariam uma crise política sem precedentes.

Antecipando os custos sociais e políticos destas medidas, os representantes do Parlamento - salvo os membros do partido de governo Acción Democrática (AD) - recusaram a assinatura da carta de intenção entre o governo venezuelano com o FMI; sem que isso levasse ao CAP e ao seu gabinete ministerial mudar sua decisão.

Aquela segunda-feira, em 27 de fevereiro, amanheceria com o aumento unilateral dos preços das passagens. A reação popular, que começou espontaneamente com a colocação de barricadas e pneus incendiados na rodoviária da cidade de Guarenas (estado Miranda), na rodoviária da cidade de Los Teques e na rodoviária do Nuevo Circo na cidade de Caracas, expandiu-se rapidamente pelas ruas de outras cidades do país... E as favelas começaram a descer dos morros.

As barricadas foram se espalhando por todas as ruas e os comércios começaram a ser saqueados em um ato de redenção da população frente ao açambarcamento, à escassez e à especulação nos preços dos produtos. Sobre este primeiro momento, o bispo jesuíta Arturo Sosa diz que os protestos foram dirigidos a

$$
\begin{aligned}
& \text { arrebatar de las bodegas, supermercados y tiendas los } \\
& \text { produtos que les eran negados, bien por el acaparamiento } \\
& \text { deshonesto de estos días o por el nivel de ingresos en } \\
& \text { continuo descenso que le ha quitado a la mayoría de los } \\
& \text { habitantes del país hasta la expectativa de conseguirlos. (...) } \\
& \text { La gente pobre, al sentir su fuerza y verse con las manos } \\
& \text { llenas, experimentó contento, euforia. (SOSA, 1989: 101). }
\end{aligned}
$$

O sentimento de algarabía constituiu-se no clima que animou as vontades durante a explosão popular: "me siento feliz - decía una muchacha -, yo nunca había manifestado, siempre dicen que son estudiantes revoltosos, pero ahora lo hago y me siento bien, puedo decir lo que quiero y protestar contra lo que me molesta" (COLMENAREZ, 1989: 28). O testemunho revela um agir, uma vontade e uma experiência de libertação que antes parecia estar reservado para outros atores políticos. Trata-se de uma algarabía gerada pela possibilidade de 
se posicionar frente ao que oprime e, por um momento, mudar de forma favorável a correlação de forças. Até então, os protagonistas das ruas "quentes" foram fundamentalmente os estudantes ${ }^{10}$, os quais ocuparam o lugar abandonado pelos sindicatos e pelos partidos de esquerda - moderados por uma estratégia cada vez mais institucionalizada e acomodada à ordem política do regime "puntofijista".

Perante o caos gerado por esta emergência acontecimental e imprevista, a estratégia da esquerda moderada foi a de restabelecer a ordem institucional do regime, combater e frear a incontível força da população insurgente e canalizála para uma alternativa eleitoral. Esse foi o conteúdo do apelo que fizera, dias depois, Andrés Velásquez, líder do partido de esquerda Causa R: "Yo termino con un llamado a toda la población que se alzó hace unos dias, para que orientemos esa protesta pasándole factura al paquete económico de CAP en las próximas elecciones municipales, de alcaldes y gobernadores" (VICENZO, 1989: D/13). A estratégia desta esquerda não reparava na mensagem da rebelião, ou seja, que a explosão era tanto uma expressão da crise desse regime, quanto o ponto de início de sua queda.

Desta forma, a disposição de desafio da população, inscrita no JÁ NÃO MAIS! e no ATÉ AQUI!, tem por trás esse sentimento de algarabía encarnado tanto nas subjetividades e forças que produziram o "acontecimento", quanto na sua determinação por recuperar por si mesmas o que lhes fora negado. A paciência e a capacidade de resistência da população pobre e oprimida da sociedade venezuelana, a qual padecera os rigores da crise econômica iniciada no "viernes negro"11, quebrou-se nessa explosão social em 27 de fevereiro e,

\footnotetext{
${ }^{10}$ Os estudantes de ensino médio e universitário desempenharam um papel preponderante nas lutas daqueles anos contra o regime "puntofijista". Os protestos pela passagem estudantil, contra as detenções e assassinatos de líderes estudantis, os episódios na cidade de Mérida, no ano 1987, e as tradicionais manifestações nas portas da Universidade Central de Venezuela (UCV), foram algumas das expressões do movimento estudantil como ator político. Para maiores referências sobre o papel do movimento estudantil nas décadas de 80 e 90 , ver o documentário Pégale candela (SZEPLAKI, 2005), o romance de testemunho Lo que fue dictando el fuego (HERNÁNDEZ, 2015) e o livro Protesta estudiantil y represión en Venezuela. 1983-1993 (Rada Aragol; Contreras, 2010).

${ }^{11}$ O "viernes negro", acontecido na Venezuela na sexta-feira 18 de fevereiro de 1983, corresponde à data na qual o valor do bolívar com respeito ao dólar sofreu uma abrupta queda, a qual afeitou a estabilidade da economia do país nos anos seguintes.
} 
tanto os sindicatos quanto as organizações políticas - de esquerda e de direita -, ficaram transbordados por aquele "acontecimento".

A estratégia de moderação e de institucionalização assumida por parte dos partidos de esquerda os afastou mais ainda da população. Apenas o movimento estudantil e algumas organizações políticas menores, de cunho autonomista como a Desobediência Popular, mantiveram a relação com aquela. Assim, a rebelião nesse 27 de fevereiro criou suas próprias regras e mecanismos de luta e ação, com a ajuda dos estudantes que, desta vez, participaram de forma distinta e sem um corpo unificado nos protestos, nas barricadas, nos fechamentos de rua e na defesa das favelas contra os policiais. A participação deles foi de acompanhamento, não de liderança unificada, pois o que acontecia não fazia parte de um plano ou de uma situação previsível e também não contava com "vanguarda" partidária.

O testemunho de Juan António Hernández, em seu romance Lo que fue dictando el fuego, mostra a forma como os estudantes receberam e perceberam o que se passava nesse 27 de fevereiro:

Siempre se habla de estallido para describir el Caracazo y ciertamente lo fue. Pero el inicio de esa explosión, para nosotros, fue de acción retardada o en cámara lenta. Porque aunque llegamos a la UCV muy temprano, ese 27, lo que hicimos fue estar a la expectativa, escuchando rumores que iban llegando de manifestaciones en Guarenas y en el terminal del Nuevo Circo de Caracas. Acompañamos a un grupo grande de liceístas que apareció, de la nada, para trancar las entradas de la universidad. Al mismo tiempo algunos dirigentes estudiantiles llamaban a salir a protestar al centro de la ciudad. (HERNÁNDEZ, 2015: 71).

Enquanto os protestos iam in crescendo, e enquanto uma multidão de pessoas juntava-se à algarabía que lhes mostrava como era possível quebrar o regime que os mantinha oprimidos, a polícia não conseguiu restabelecer a ordem e a paz nas ruas. Em alguns casos, e pela ausência de comando único e de capacidade de resposta por parte dos corpos repressivos, os soldados e policiais participaram na dinâmica de auto-organização incipiente da população. Trata-se de uma dinâmica marcada pelo sentimento de libertação e de solidariedade e de um momento no qual o "acontecimento" transbordou os 
mecanismos que garantiram a ordem institucional do Estado, conseguindo reverter, embora por breve tempo, a fome, a escassez e o afastamento daquilo que sempre lhes foi negado.

Con el producto de los saqueos las masas (...) lograron llenar las neveras vacías desde hace meses. Dieron a los niños la comida que (...) estaba desaparecida o con precios inalcanzables. Expropiaron masivamente a los especuladores, a los patronos que desabastecieron el mercado para 'remarcar' precios. (COLMENAREZ, 1989: 44 e seq.).

Nessa festa na qual os oprimidos conseguiram legitimar suas ações e terem em suas mãos a possibilidade de criar outra história e outra política, a credibilidade na institucionalidade democrática "puntofijista" foi quebrada, bem como foi relegada à "ilegalidade" a política do governo. Trata-se do momento de quebra do real impulsionado pelo sentimento de "algarabía messiânica", na medida em que constitui um instante de alegria e de afirmação "poiética" coletiva que abre as janelas para o futuro, instaura uma nova situação e inaugura outras possibilidades e formas de organização social e de orientação histórica.

Neste primeiro movimento, o Caracazo foi - e eis uma parte da minha hipótese fundamental - um "acontecimento", na medida em que foi uma quebra do próprio real.

(...) un conductor, hecho el pendejo, quiso colarse y fue detenido por los manifestantes: resultó ser un oficial de la GN y no se sabía qué hacer con él. Una asamblea rápida tras la barricada discutía sobre la conveniencia de dejarlo pasar o no. Un grupo de policías observaba la discusión, sin participar en ella. Tomada la decisión, uno de los policías fue a informar: 'Mi oficial, me permito decirle que la gente decidió que no podía pasar, es mejor que retroceda' (COLMENAREZ, 1989: 37).

As favelas converteram-se em territórios controlados pela organização popular, a qual se foi desenvolvendo com as ferramentas de luta dos estudantes e com as armas dos grupos "irregulares" que, nesse momento, viraram aliados. O regime de assembleia para a tomada de decisões substituiu as formas hierárquicas e tradicionais para as decisões coletivas. As táticas de guerrilha conseguiram impedir a entrada da polícia e houve zonas e favelas nas quais, 
inclusive, o Exército não conseguiu entrar (COLMENAREZ, 1989). A "algarabía messiânica" espalhou-se com instrumentos e sujeitos distintos das formas clássicas de luta e de organização. Os vínculos sociais, tecidos por anos entre os vizinhos nas favelas, estabeleceram formas organizacionais e de coesão mais fortes e confiáveis, marcadas por um caráter horizontal e democrático.

Porém, a algarabía não conseguiu ir além da sua manifestação imediata. Em declarações veiculadas em 09 de março desse mesmo ano para El Nacional, um dos jornais mais importantes do país, o ex-presidente da República da Venezuela, Luis Herrera Campins, enfatizou nas dimensões e nos limites da rebelião, bem como na ausência de estratégia, por parte dos insurgentes, a qual tornou "mais fácil" o restabelecimento da ordem estatal:

En tres días vimos lo que jamás habíamos presenciado en ninguna época en el país, y si no llegó a mayores esa turbulencia social, fue por su espontaneidad inicial y su falta de conducción y orientación. Si el gobierno no cayó, ni el sistema democrático actual se destruyó, fue por la razón anterior, pues en los dos primeros días del conflicto se observó una gran ausencia de la dirección política y social venezolana (COLMENAREZ, 1989: 82).

Desta forma, a explosão acontecimental de fevereiro foi apenas uma "chance" que, embora desestabilizara o regime "puntofijista" e vivenciara novas formas de organização social no momento da sua emergência, não conseguiu ultrapassar e se sobrepor ao que aconteceria nos dias seguintes...

\section{Segundo movimento: a tragédia traumática}

Às 16hs, em 28 de fevereiro, por rede nacional, o governo venezuelano anunciou a suspensão das garantias constitucionais, aprovada segundo o Decreto Presidencial No. 49: "Se suspenden en todo el territorio nacional las garantías establecidas en los ordinales 1, 2, 6 y 10 del artículo 60, y de los artículos 62, 64, 66, 71, 115 de la Constitución” (EL NACIONAL, 1989: D/14). Trata-se dos artigos relativos aos direitos à liberdade individual (art. 60), inviolabilidade do lar (art. 62), liberdade de trânsito (art. 64), liberdade de expressão (art. 66), liberdade de reunião (art. 71) e direito à manifestação pacífica (art. 115). 
Depois de acordar do estado de choque e diante da inabilidade da polícia e da Guarda Nacional de manterem e restituírem a ordem institucional, o governo tomou a medida extrema de dissolver as garantias democráticas e convocar o Exército às ruas.

No entanto, nos primeiros momentos, a população das favelas se manteve nas ruas e nas barricadas para impedir a entrada do Exército nas suas casas. Nesse instante, o Exército assassinava e a população se multiplicava e reagia. Mesmo com a firmeza e superioridade das forças repressivas, houve confronto com a resistência da população, que acabou apenas dias depois.

O poder de fogo do Exército foi comprometendo a força e a coragem de um povo que havia reagido às políticas neoliberais, saindo às ruas e reorientando, mesmo que instantaneamente, o regime de propriedade e de organização social. Desta forma e aos poucos, a algarabía foi banida pela "monstruosidade" falando nos termos de Zizek. Com medidas extremas de repressão, o governo desnudou o mito da paz social e da democracia, revelando a impossibilidade do consenso em tempos de crise e de ameaça à ordem social e política instituídas. O "acontecimento" transfigurou-se na sua dimensão transcendental, ou seja, na quebra do marco representacional e simbólico com o qual se sustentara o regime democrático "puntofijista" venezuelano.

A maior parte dos soldados do Exército que esteve encarregada da repressão, veio das cidades do interior do país. O desconhecimento da vida na metrópole, bem como a incerteza pelo que acontecia, alimentaram sua insegurança e seu medo. Sobre esse aspecto, o bispo Matías Camuña narra em um testemunho:

\footnotetext{
A mí se dirigieron un policía y un soldado. El policía me confesó, llorando: 'Yo no sé qué me ha pasado, pero maté a mucha gente, y las boté'. Y el soldado me contó: 'Yo me expuse a que me fusilaran porque no quería seguir órdenes. A mí me trajeron de Barinas, colocaron el tanque militar cerca del estadio de Palo Verde, y me ordenaron disparar a cualquier cosa extraña que se moviera. Pero yo no podía, me recordaba de mi familia, a los que tenía que disparar eran como mi familia. (DEFENSORÍA DEL PUEBLO, 2007: 29 e seq.).
} 
Com esses confrontos morais e empáticos os soldados, sob mandato do governo, acabaram atirando em seus afins, criando o massacre massivo mais trágico acontecido na história contemporânea da Venezuela.

Durante esses dias, os centros de saúde tornaram-se hospitais de guerra. $\mathrm{Na}$ edição de 2 de março, o jornal El Nacional resenhou o testemunho de uma mulher narrando os primeiros momentos do massacre no Hospital Pérez Carreño, na cidade de Caracas:

Con la desconfianza de estos días solo dijo que se llamaba Thaís. Pero contó que únicamente el martes llegaron 30 muertos al hospital y 'aproximadamente tres mil heridos', la mayoría por armas de guerra'.

- Al principio, casi todos eran hombres jóvenes. Luego comenzaron a ingresar mujeres, niños y hasta ancianos (...). $\mathrm{Vi}$ a un niño de nueve años con una enorme lesión de bala en el pecho (...). Fueron horas terribles. Parecía una guerra. (TERÁN, 1989: 108).

No dia 4 de março, o jornal Últimas Noticias resenhou:

En una fosa común han sido enterrados 120 cadáveres durante la madrugada y la mañana de ayer con el objeto de descongestionar la morgue de Bello Monte, que se encuentra abarrotada después de cinco días de violencia en el área metropolitana. En una decisión de los ministerios de Sanidad y de Justicia, los efectivos de Defensa Civil improvisaron una fosa común, en el lugar conocido como La Peste en el Cementerio General del Sur, donde sepultaron a más de un centenar de hombres, mujeres y niños. (RODRÍGUEZ, 1989: $10)$.

Os jornais não paravam de mostrar cifras alarmantes. Seis dias depois da rebelião, uma manchete de jornal anunciava: "Más de 800 muertos en Caracas según lista extraoficial en seis días de violencia”, apresentando no subtítulo: "Heridos pasan de 5 mil según cifras", "La morgue guarda silencio y se niega a dar información" (ÚLTIMAS NOTICIAS, 1989: 12). Segundo o Informe de situación de derechos humanos en Venezuela (octubre de 1988-septiembre de 1989), apresentado pela organização de direitos humanos Provea, "El número de muertos llega a 276 según cifras oficiales, a 379 según datos ofrecidos por parlamentarios de Causa $\mathrm{R}$ y a un millar según fuentes estudiantiles y de corresponsales extranjeros" (PROVEA, 1989: 48). Lamentavelmente, ainda 
hoje não há informação certa do número de mortos e de feridos que restou como saldo do massacre.

Assim, o restabelecimento da ordem institucional no país foi possível pela suspensão aberta e visível das garantias democráticas para toda a população e não apenas para os movimentos sociais e organizações da esquerda não institucionalizadas. Aliás, tanto a rebelião quanto a repressão geraram uma ruptura do sistema da democracia "puntofijista", bem como do seu marco simbólico e, talvez, a primeira advertência à ordem financeira internacional.

Os dias do Caracazo foram dias de surpresa que mexeram com a tranquilidade das elites políticas, as quais começaram reconhecer, em seus discursos, a desigualdade social, os impactos das medidas neoliberais impostas pelo FMI e a ruptura que aquele episódio gerara no sistema democrático venezuelano. O Caracazo rompeu, como manifestou Rafael Caldera, expresidente da República e senador vitalício no Congresso da República, o "escaparate 12 de la democracia" na América Latina. "El escaparate lo rompieron los hambrientos que no quieren someterse a los moldes férreos del Fondo Monetario Internacional" (ALVARADO, 1989: 7).

As dimensões do Caracazo como ameaça real ao regime "puntofijista", como potencialidade emancipadora, como evidência do fracasso do modelo rentista de desenvolvimento nacional, como ruptura traumática da imposição do neoliberalismo em nosso país e como quebra do aparato simbólico da ordem estabelecida, expressam-se nas comprometedoras declarações que dera o próprio presidente da República, Carlos Andrés Pérez, para um canal de televisão mexicano:

Nosotros hemos simbolizado en las medidas del Fondo ${ }^{13}$ lo que nos sucede, pero tenemos que decir con franqueza que es la política que han fijado las grandes naciones industrializadas para obligarnos a pagar nuestras obligaciones en condiciones en que no podemos hacerlo racionalmente (ÚLTIMAS NOTICIAS, 1989: 54).

\footnotetext{
${ }^{12}$ Vitrine em português.

${ }^{13}$ Se refiere al Fondo Monetario Internacional.
} 
Desta forma, interrompe-se aquele acontecimento que quebrou o muro real e simbólico do "puntofijismo" e que revelou possibilidades insuspeitas que foram para além do regime, bem como a "monstruosidade" escondida por trás da ilusão do modelo rentista venezuelano.

Considerações finais: O Caracazo, um cisne negro para a hipótese presentista

Após descrever o Caracazo à luz de suas particularidades, ressaltando as forças, tensões e possibilidades que emergiram nele, podemos dizer que ele foi um "acontecimento" que alterou a ordem social e política da história recente na Venezuela.

Em primeiro lugar, o Caracazo foi uma explosão imprevisível que virou o curso normal das coisas e surpreendeu, não apenas os atores políticos de esquerda e de direita, mas a elite empresarial do país e a ordem financeira internacional. Em segundo lugar, sua emergência abriu um instante de vazio de poder, o qual permitiu a produção momentânea de outras dinâmicas sociais e organizativas. Em terceiro lugar, da sua irrupção emergiram novos sujeitos, novas forças políticas e novas formas de organização que conseguiram ultrapassar, embora que instantaneamente, as estruturas do poder econômico, político e institucional no país, instaurando suas próprias regras e formas de autogoverno. Em quarto lugar, sua emergência revelou o real e derrubou o mito da democracia "puntofijista" na Venezuela.

Além disso, o Caracazo foi a "contraface" da derrota das apostas emancipatórias, na medida em que foi uma afronta contra o avanço neoliberal. Enquanto a Europa assistia à queda do Muro de Berlim e do bloco soviético, na Venezuela as forças subterrâneas dos excluídos e explorados emergiram e desafiaram os poderes dominantes, indo à contracorrente do espírito das resignações que estava se espalhando pelo mundo. Na Europa, caiam os muros das alternativas emancipatórias, na Venezuela, "neste canto da América", caiam 
os muros do mito da democracia "puntofijista" que, ainda hoje, não conseguiu se restituir.

Apesar da afirmação de Fukuyama sobre a vitalidade e boa saúde do liberalismo político e econômico no mundo (FUKUYAMA, 1990: 18), poderse-ia dizer que o Caracazo foi um "cisne negro" para esta afirmação, enquanto a tentativa da sua inserção não teve sucesso. Em primeiro lugar, porque a tentativa de implementação das medidas neoliberais gerou uma ruptura da estabilidade democrática: a ilusão de paz social e a governabilidade "homogênea" entre as classes foi quebrada, a emergência intempestiva e violenta dos setores populares contra as medidas econômicas gerou temporalmente um vazio de poder e a repressão desmedida que implementara o governo "democrático" venezuelano para levar adiante tais medidas, transgrediu garantias democráticas fundamentais. Em segundo lugar, porque as lutas de resistência que derivaram nos anos seguintes do Caracazo impediram às políticas neoliberais serem implementadas por completo na Venezuela.

Porém, a impotência desta "chance" de ir para além do regime e de consolidar novas dinâmicas sociais e políticas mostra as falências estratégicas que participaram nela.

As peculiaridades que dão conta da "natureza" intempestiva e acontecimental do Caracazo e da sua contraposição à tese presentista, permitem fundamentar a tese da história aberta para a compreensão de nosso presente, tentando derrubar os muros com os quais se pretende fechar o futuro. Frente à catástrofe presentista e ao paraíso edénico do historicismo progressista, a história aberta e estratégica assume a incerteza do futuro como móvel da atividade práxica na recuperação das apostas emancipatórias e da construção de outras possibilidades para a história factual do futuro, tendo em conta que não há tendências definitivas. No entanto, e pelas limitações deste artigo, deixo para uma reflexão posterior o estabelecimento das possíveis ligações históricas do passado e do futuro relativos ao Caracazo, tendo como fundamento a perspectiva teórica que este artigo subscreve. 


\section{Referências}

ALVARADO, Daniel. Caldera atribuye al hambre los saqueos. Dijo al iniciar su intervención en el Senado. Últimas Noticias, Caracas, p. 7, 2 mar. 1989.

BADIOU, Alain. El ser y el acontecimiento. Tradução Raúl Cerdeiras, Alejandro Cerletti e Nilda Prados. Edição Raúl Cerdeiras e Alejandro Cerletti. Buenos Aires: Manantial, 2003. 582 p.

L'Hypothèse communiste. Paris: Lignes, 2009. 192 p.

La idea del comunismo. In: HOUNIE, A. (Comp.). Sobre la idea del comunismo. Buenos Aires: Paidós, 2010. p. 17-31.

BENJAMIN, Walter. La dialéctica en suspenso: Fragmentos sobre la historia. Tradução Pablo Oyarzún Robles. Santiago de Chile: LOM Ediciones, 2009. 176 p.

BENSAÏD, Daniel. Resistencias: Ensayo de topología general. Tradução María Virginia Góngora. Madrid: Ediciones de Intervención Cultural / El Viejo Topo, 2006. 190 p.

Tiempo histórico y ritmos políticos. In:

La política como arte

estratégico. Tradução Revista Viento Sur e Alfonso Serrano. Madrid: Viento Sur / La Oveja Roja, 2013. p. 103-114.

BORGES, Jorge Luis. El jardín de los senderos que se bifurcan. Ficciones. In: Obras completas. 1923-1972. Buenos Aires: Emecé Editores, 1984. p. 472-480.

COLMENAREZ, Elio. La insurrección de Febrero: (análisis para la lucha revolucionaria). Caracas: Ediciones La Chispa, 1989. 123 p.

DEFENSORÍA DEL PUEBLO. A 18 años de El Caracazo: Sed de justicia. Informe oficial. Defensoría del Pueblo, Caracas, 2007. 171 p.

DENIS, Roland. Los fabricantes de la rebelión. Caracas: Editorial Primera Lçinea / Editorial Nuevo Sur, 2001.

DENIS, Roland; GÓMEZ, Teresa; MENDOZA, Ramón. 27 F. Testimonios. Diacrítica, Caracas, n. 7, p. 44-61, s.f.

DUSSEL, Enrique. Transmodernidad e interculturalidad (interpretación desde la filosofía de la liberación). In: FORNET-BETANCOURT, Raul (Ed.). Crítica intercultural de la filosofía latinoamericana actual. Madrid: Trotta, 2004. p. 123-160. 
ECHEVERRÍA, Bolívar. Modernidad y capitalismo. In:

Discurso crítico y modernidad. Bogotá: Ediciones Desde Abajo, 2011. p. 45-93.

EL MUNDO. Cambio único y liberación de la economía anunció CAP esta mañana al asumir la Presidencia de la República. El Mundo, Caracas, p. 1, 2 fev. 1989.

EL NACIONAL. Suspendidas garantías constitucionales. El Nacional, Caracas, p. D/1, 1 mar. 1989.

FUKUYAMA, F.¿El fin de la historia? Estudios Públicos, Santiago de Chile, n. 37, p. 5-31. 1990.

GUERRILLA COMUNICACIONAL MÉXICO. EE.UU.: Antifascistas armados ya recorren las calles de Charlottesville. 16 ago. 2017. Disponível em: $<$ http://gcm-mx.com/noticias/internacionales/ee-uu-antifascistas-armados-yarecorren-las-calles-charlottesville/>. Acesso em: 21 jul. 2019.

GUMBRECHT, Hans Ulrich. Nosso amplo presente: o tempo e a cultura contemporânea. São Paulo, Brasil: Editora Unesp, 2015. 153 p.

HARTOG, François. Regímenes de historicidad. Presentismo y experiencias del tiempo. México D.F.: Universidad Iberoamericana, 2007. 243 p.

HERNÁNDEZ, Juan Antonio. Lo que fue dictando el fuego. Caracas: Trinchera, 2015. $95 \mathrm{p}$.

ITURRIZA LÓPEZ, Reinaldo. 27 de Febrero de 1989: interpretaciones y estrategias. Caracas: Fundación El Perro y la Rana, 2006.

KOSELLECK, Reinhart. Futuro pasado. Para una semántica de los tiempos históricos. Buenos Aires / Barcelona: Paidós, 1993. 369 p.

LÖWY, Michel. Walter Benjamin: aviso de incendio. Una lectura de las tesis "Sobre el concepto de historia". Tradução Horacio Pons. Buenos Aires: Fondo de Cultura Económica, 2012. 187 p.

PARTIDO SOCIALISTA DE LOS TRABAJADORES. Venezuela entra a la revolución continental. Conferencia Nacional Extraordinaria del PST (Junio, 1989). Caracas: La Chispa, s.p, jun. 1989.

PÉGALE Candela. Direção: Alejandra Szeplaki. Produção: Daniel Jerozolimski. Edição: Sergio Marcano. Roteiro: Alejandra Szeplaki. Ideia original: José Roberto Duque e Juan Antonio Hernández. Música: Daniel Zahalka. Caracas: Villa del Cine. Produzido por Estrella Films, Ministerio de la Cultura, 2005. Longametragem (90 min), color, vídeo digital. Disponível em: 
$<$ https://www.youtube.com/watch?v=bCXI8TeEW68 $>$. Acesso em: 27 jul. 2019.

PEREIRA, Matheus; ARAUJO, Valdei. Reconfigurações do tempo histórico: presentismo, atualismo e solidão na modernidade digital. Revista da Universidade Federal de Minas Gerais, Belo Horizonte, n. 23, p. 271-297, jan.-dez. 2016.

PROVEA. Informe de situación de derechos humanos en Venezuela (octubre de 1988-septiembre de 1989): informe anual. Caracas: Provea, 1989. $108 \mathrm{p}$.

RADA ARAGOL, YASMÍN; CONTRERAS, ORLANDO. Protestas estudiantiles y represión en Venezuela: 1983-1993. Caracas: Archivo General de la Nación / Centro Nacional de Historia, 2010.

RODRÍGUEZ, Gustavo. 120 cadáveres enterrados en fosa común para descongestionar la morgue de Bello Monte. Últimas Noticias, Caracas, p. 10, 4 mar. 1989.

SOSA, Arturo. ¿Qué fue lo que pasó? Revista SIC, Caracas, n. 513, p. 101106, abr. 1989.

SUTHERLAND, Manuel. El 27 de Febrero de 1989 en Venezuela. Diacrítica, Caracas, n. 7, p. 40-43, 2009.

TERÁN, José Gregorio. Los sucesos en la prensa diaria. Revista SIC, Caracas, n. 513, p. 107-110, abr. 1989.

ÚLTIMAS NOTICIAS. CAP culpa al Fondo Monetario y acreedores de la violencia social en Venezuela. Últimas Noticias, Caracas, p. 54, 3 mar. 1989.

Más de 800 muertos en Caracas según lista extraoficial en seis días de violencia. Últimas Noticias, Caracas, p. 12, 5 mar. 1989.

VICENZO, Teresa de. Andrés Velásquez: el gobierno ya fracasó. El Nacional, Caracas, p. D/7, 11 mar. 1989.

ZIZEK, Slavoj. Acontecimiento. Madrid: Sexto Piso, 2014. 181 p.

Recebido em: 11 de fevereiro de 2020

Aceito em: 10 de março de 2021 